04

\title{
Поляризационно-чувствительные регистрирующие среды для голографии на базе красителя-флуорофора lucifer yellow
}

\author{
() В.Г. Шавердова, С.С. Петрова, А.Л. Пурцеладзе, В.И. Тарасашвили, М.В. Тарасашвили \\ Лаборатория голографической записи и обработки информации, Институт кибернетики, \\ Грузинский технический университет, \\ 0186 Тбилиси, Грузия \\ e-mail: shaverdova@inbox.ru
}

Поступила в редакцию 26.07.2019 г.

В окончательной редакции 26.07.2019 г.

Принята к публикации 01.11.2019 г.

Созданы поляризационно-чувствительные голограммные среды на основе матриц из поливинилпирролидона и желатины, в состав которых были введены красители Lucifer Yellow и Coumarin 466. С использованием линейно поляризованного излучения лазера LSR 405 NL-50 $(\lambda=405 \mathrm{~nm})$ в люминесцентном фотоанизотропно-гиротропном материале записана мультиплексная динамическая голограмма Денисюка. Методом поляризационно-люминесцентной голографии измерены фотоанизотропные характеристики пучка, соответствующего восстановленному мнимому изображению поля объекта. Измерены поляризационные спектры и спектры интенсивности фотолюминесценции восстановленного изображения в зависимости от состава регистрирующей среды. Показана возможность мультиплексной записи и наблюдения за несколькими изображениями анизотропно-гиротропного объекта одновременно, если они закодированы разными частотами эмиссии и (или) состоянием поляризации. Комбинирование недеструктивного поляризационнолюминесцентного голографического метода измерения с другими люминесцентными спектроскопическими методами значительно расширяет область применения данного метода, резко повышает общую информативность исследования.

Ключевые слова: голография, красители, регистрирующие среды, поляризация.

DOI: $10.21883 /$ OS.2020.02.48966.238-19

\section{Введение}

После появления основополагающих работ Ш.Д. Какичашвили с предложением нового поляризационноголографического метода записи значительно возросло применение голографии для решения различных научно-практических задач: 1) переработки оптической информации и создания систем оптической памяти; 2) коррекции излучения, генерируемого лазером со сложным распределением поляризации по фронту; 3) создания дифракционных элементов с переменным профилем анизотропии и гиротропии и т.д. [1-4].

Как известно, основная сущность нового поляризационно-голографического метода заключается в том, что в качестве голограммных сред используются светочувствительные материалы, приобретающие под воздействием поляризованного излучения анизотропию и гиротропию поглощения (эффект Ф. Вейгерта); это позволяет моделировать состояние поляризации суммарной волны. Зарегистрированная в подобной среде голограмма однозначно реконструирует векторное поле объекта. Отсюда следует, что вопрос о регистрирующей среде в поляризационной голографии является центральным, это определяет особый интерес и требования к регистрирующим материалам [5-7]. В работе [8] нами было предложено использовать в голографии среды, спектр люминесценции которых дает отклик на состояние поляризации облучающего излучения.

Поляризационно-чувствительные люминесцентные регистрирующие среды обладают рядом преимуществ по сравнению с поглощающими средами, в частности:

- сверхвысокая чувствительность;

- высокая скорость отклика - процесс люминесценции происходит в наносекундной шкале времени, что позволяет с успехом использовать его в задачах динамической поляризационной голографии;

- высокое пространственное разрешение, что позволяет проводить исследования различных наноструктурных систем на микроскопическом уровне;

- совместимость с живыми организмами - исследования видимым люминесцентным светом не влияют на процессы, происходящие в живой клетке.

Использование поляризационно-чувствительных люминесцентных регистрирующих сред предполагает возникновение совершенно новых возможностей и направлений в голографии, новые пути регистрации и преобразования электромагнитных волн. Методами поляризационно-люминесцентной голографии могут решаться ранее недоступные для голографии задачи, в том числе связанные с исследованием молекулярных структур люминесцирующих веществ; мультиплексная запись и наблюдение за несколькими анизотропно-гиротропными объектами одновременно, если они закодирова- 
<smiles>CCN(CC)c1ccc2ccc(=O)oc2c1</smiles><smiles>NCCCCC(N)C(=O)O</smiles>

Рис. 1. Структурные формулы красителей Lucifer Yellow (a) и Coumarin $466(b)$, аминокислоты лизина $(c)$.

ны разными частотами эмиссии и (или) состоянием поляризации; возможность варьирования спектральным составом излучения как на стадии записи, так и на стадии считывания информации. Подобное обобщение голографического метода интересно как в научном отношении, так и с точки зрения возможности его использования в практике, поскольку с исследованием структур люминесцирующих анизотропно-гиротропных материалов связано решение большого числа разнообразных задач в медицине, астробиологии, геологии, минералогии и т.д. $[9,10]$. Методами поляризационнолюминесцентного голографического измерения авторами были исследованы поляризационно-люминесцентные характеристики разнообразных поляризационно-чувствительных люминесцентных сред; измерены поляризационные спектры и спектры фотолюминесценции $(\mathrm{PhL})$ образцов в зависимости от их химической структуры, состава и состояния поляризации индуцирующего излучения. В частности, в работах [11] были исследованы битуминозные материалы - сырая нефть из различных буровых Сацхенинского месторождения и автомобильные бензины различных марок: AI-92, AI-95 и AI-98. Результаты исследования представляют интерес в нефтяной промышленности при диагностике нефтяных загрязнений, контроля качества углеводородных топлив и их идентификации. Как указывалось выше, получение новых высокочувствительных регистрирующих сред представляется весьма актуальным для решения задач поляризационно-люминесцентной голографии.

Целью данной работы являлось создание и исследование регистрирующих сред, в состав которых введены флуоресцирующие красители типа Lucifer Yellow и Coumarin 466. Они обладают выраженными эффектами векторных реакций и отвечают специфическим требованиям, необходимым для успешного решения задач поляризационно-люминесцентной голографии, в частности, имеют широкий спектральный диапазон поляризованной люминесценции, высокий квантовый выход, заметный стоксов сдвиг. Указанные красители широко применяются в качестве флуоресцентных маркеров и зондов для определения гормонов, лекарственных препаратов, наркотиков, в клинической химии, биологии ит.п. $[12,13]$.
На наш взгляд, комбинирование недеструктивного и безопасного для исследования различных биологических систем поляризационно-люминесцентного голографического метода с аналогичными стандартными поляризационно-люминесцентными спектральными методами измерения резко повышает общую информативность исследования и значительно расширяет область применения данного метода.

\section{Материалы и методика измерений}

В данной работе мы представляем регистрирующие композиции, в состав которых были введены красители Lucifer Yellow (структурная формула - рис. 1,a) и Coumarin 466 (рис. 1,b).

В одну из композиций была добавлена аминокислота лизин (рис. 1,c), спектр люминесценции которой представляет собой сложную по форме и широкую спектральную полосу, расположенную в интервале $(310-500 \mathrm{~nm})$. Красители Lucifer Yellow и Coumarin 466 вводились в один из пленкообразующих полимеров: поливинилпирролидон (PVP) и желатина (Jel). Результаты проведенных ранее исследований показали, что фотоанизотропные свойства регистрирующих сред зависят от структуры матрицы и красителя [14]. Матрица желатины относится к нейтральным, имеет форму глобулярного клубка с переменным значением свободного объема между отдельными сегментами макромолекулы желатины. Водорастворимые азокрасители, диссоциируя в водном растворе, могут присоединяться к молекулам желатины, имеющей амфотерные свойства, или же диффундировать внутри свободного объема между отдельными фрагментами молекулы желатины. PVP относится к химически активным матрицам. Его активность связана с наличием атома азота в пиррольном кольце молекулы, благодаря чему она приобретает способность к комплексообразованию с молекулами красителя.

В качестве метода исследования полученных фотоанизотропно-гиротропных люминесцентных сред был использован метод поляризационных спектров. С его помощью удается определять взаимное расположение поглощающих и излучающих осцилляторов в молекулах, 


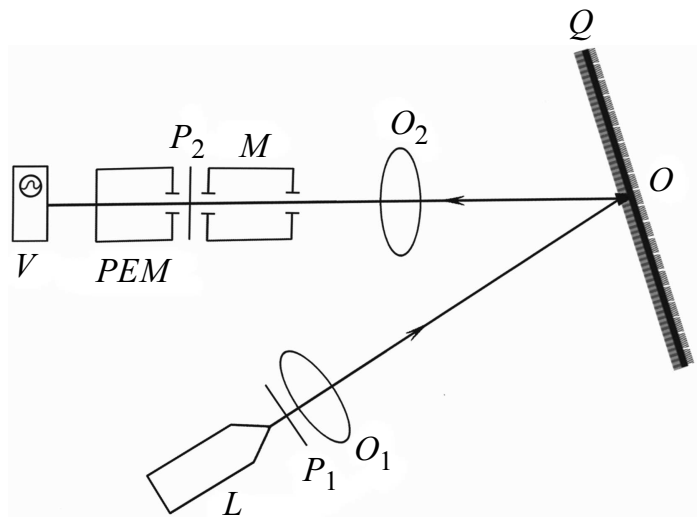

Рис. 2. Оптическая схема голографического поляризационного спектрофлуориметра: $L-$ лазер, $P_{1}-$ линейный поляризатор (призма Глана), $O_{1}, O_{2}-$ объективы (коллиматоры), $O$ - объект (плоское зеркало с внешним алюминированием), $Q-$ динамическая поляризационно-люминесцентная голограмма, $M$ - монохроматор; $P_{2}$ - анализатор, $P E M-$ фотоумножитель РМТ-62, $V$ - измерительное устройство.

а также устанавливать связь между симметрией молекул и степенью анизотропии индуцированной фотолюминесценции. Отметим также, что поляризационные спектры тесно связаны с химической структурой исследуемых веществ и в некоторых случаях могут быть более характерными, чем спектры поглощения и люминесценции.

Спектры поглощения получены на спектрофотометре Specord UV-VIZ, модифицированном для поляризационных измерений. Количественные измерения фотоанизотропных характеристик индуцированной поляризованной фотолюминесценции проводились на голографическом поляризационном спектрофлуориметре, собранном нами на основе монохроматора UM-2. Установка давала возможность записи и реконструкции динамических поляризационных люминесцентных голограмм Денисюка; была снабжена поляризационными призмами Глана, что давало возможность проводить измерения фотоанизотропных и фотогиротропных характеристик индуцированной поляризованной люминесценции полученных сред для построения поляризационных спектров.

Схема голографического поляризационного спектрофлуориметра показана на рис. 2. На исследуемых образцах проведена серия экспериментов по поляризационной записи люминесцентных голограмм с использованием линейно поляризованного когерентного излучения лазеpa LSR 405 NL-50 $(\lambda=405 \mathrm{~nm})$. На пути возбуждающего пучка устанавливался линейный поляризатор $P_{1}$ (призма Глана). Голограммы записывались по классической оптической схеме, предложенной Ю.Н. Денисюком [15]. В качестве анизотропно-гиротропного объекта $O$ служило плоское зеркало с внешним алюминированием - поляризующий оптический элемент, удовлетворяющий теоретическим условиям, необходимым для адекватной реконструкции векторного поля объекта [16]. Объект располагался непосредственно за пластинкой с пробами образца на подложке и освещался линейнополяризованным излучением лазера через слой голограммной среды $C$. Отраженные от объекта волны распространялись назад к этому же слою. В результате наложения падающего и отраженного излучений возникает система стоячих волн - интерференционное поле во встречных пучках, передающее все особенности волнового фронта объекта, т.е. динамическая поляризационнолюминесцентная голограмма Денисюка $Q[17,18]$.

Пучок, соответствующий восстановленному мнимому изображению объекта, для поляризационного анализа проецировался на входную щель монохроматора $M$, откалиброванного по пропусканию и по длинам волн с точностью $\pm 1 \mathrm{~nm}$. После прохождения монохроматора $M$ (где происходит отбор длин волн из требуемого интервала спектра люминесценции и блокирование возбуждающих длин волн) он попадал на линейный поляризатор $P_{2}$ (анализатор), имеющий возможность поворачиваться относительно электрического вектора возбуждающего излучения. Далее пучок люминесценции попадал на чувствительный фотоприемник РЕМ РМТ-62, откалиброванный по спектральной чувствительности и скомпенсированный по темновому току. Электрический сигнал с РМТ поступал на измерительное устройство $V$, показания которого при различных положениях барабана UM-2 и ориентациях анализатора $P_{2}$ $\left(0^{\circ}\right.$ и $\left.90^{\circ}\right)$ относительно электрического вектора возбуждающего излучения служили для построения поляризационных спектров люминесценции. Таким образом были получены спектры интенсивности индуцированной фотолюминесценции и поляризационные спектры: спектральные зависимости степени анизотропии люминесценции и коэффициента эллиптичности поляризации восстановленного с мультиплексных голограмм поля объекта (линейно поляризованного лазерного пучка) на разных частотах эмиссии регистрирующего материала. Степень анизотропии люминесценции восстановленного поля объекта рассчитывалась по формуле $r=\frac{I_{0}-I_{90}}{I_{0}+2 I_{90}}$, коэффициент эллиптичности поляризации восстановленного поля объекта - по формуле $K_{e}=\frac{I_{90}}{I_{0}}$. Здесь $I_{0}$ и $I_{90}$ - интенсивности взаимно перпендикулярно поляризованных компонент люминесценции восстановленного поля объекта.

В нашем эксперименте для поляризационного анализа пучка, соответствующего восстановленному мнимому изображению объекта, использовалась также поляризационно-голографическая дифракционная решетка анизотропного профиля. Оптическая схема установки, приведенная на рис. 2, при несложной модификации позволяет осуществить подобный анализ, а именно после прохождения монохроматора $M$ пучок падал на поляризационно-голографическую дифракционную решетку анизотропного профиля, затем на линейный поляризатор $P_{2}$ и на фотокамеру (решетка анизотропного профиля и фотокамера на схеме не показаны).

Как известно, дифракционные решетки анизотропного профиля способны разлагать поступающее на них излу- 
чение на ортогональные (линейные и циркулярные) компоненты, направляя их соответственно в положительные и отрицательные порядки, что позволяет использовать решетки в оптических системах в качестве анализирующего элемента поляризации [19]. При считывании такой решетки эллиптически поляризованным светом, пучки +1 и -1-го порядков дифракции оказываются правои лево-циркулярно поляризованными, а отношение их интенсивностей не зависит от ориентации эллипса поляризации падающего пучка и может служить мерой его эллиптичности. В нашем случае дифракционная решетка анизотропного профиля получена на высокочувствительном фотоанизотропно-гиротропном материале на базе органического красителя ПЧЖ, введенного в желатиновую матрицу.

\section{Результаты и обсуждение}

Были измерены спектры люминесценции и поляризационные спектры пучка восстановленного поля объекта с мультиплексных голограмм, зарегистрированных в различных поляризационно-чувствительных композициях и матрицах Jel и PVP. Спектры получены при одинаковых условиях записи мультиплексных поляризационнолюминесцентных голограмм с использованием линейно поляризованного излучения лазера LSR 405 NL-50 $(\lambda=405 \mathrm{~nm}, W=30 \mathrm{~mW})$.

В состав композиции № 1 вошли: высокоэффективный флуоресцирующий краситель Lucifer Yellow и лизин, в составе композиции № 2 к красителю Lucifer Yellow добавлялся краситель Coumarin 466. Для сравнения влияния введенных допантов на спектры излучения и поляризации в качестве эталона был использован краситель Lucifer Yellow (композиция № 3). Ингредиенты были введены в водорастворимые матрицы PVP и Jel.

На рис. 3 приведено спектральное распределение интенсивности поляризованной люминесценции восстановленного поля объекта, зарегистрированного в поляризационно-чувствительных композициях на основе матриц Jel (рис. 3,a) и PVP (рис. 3,b). На рис. 3, $a$ приведен также спектр поглощения (кривая 4) композиции № 2, измеренный на спектрофотометре Specord UV-VIZ. Как видно из приведенного рисунка, стоксов сдвиг составляет $\approx 125 \mathrm{~nm}$.

Приведенные рисунки демонстрируют наличие широкого спектра поляризованной люминесценции от 400 до $650 \mathrm{~nm}$ для всех композиций. Это объясняется тем, что $\pi$-электронная система красителей типа Lucifer Yellow очень разветвленная. Молекула содержит донорные группы и ионогенную дилитиевую группу. При возбуждении молекулы красителя длиной волны $405 \mathrm{~nm}$ происходят многочисленные электронные переходы с возбужденного уровня на основной, это благоприятствует как возникновению люминесценции, так и смещению ее в длинноволновую область спектра. Интенсивность
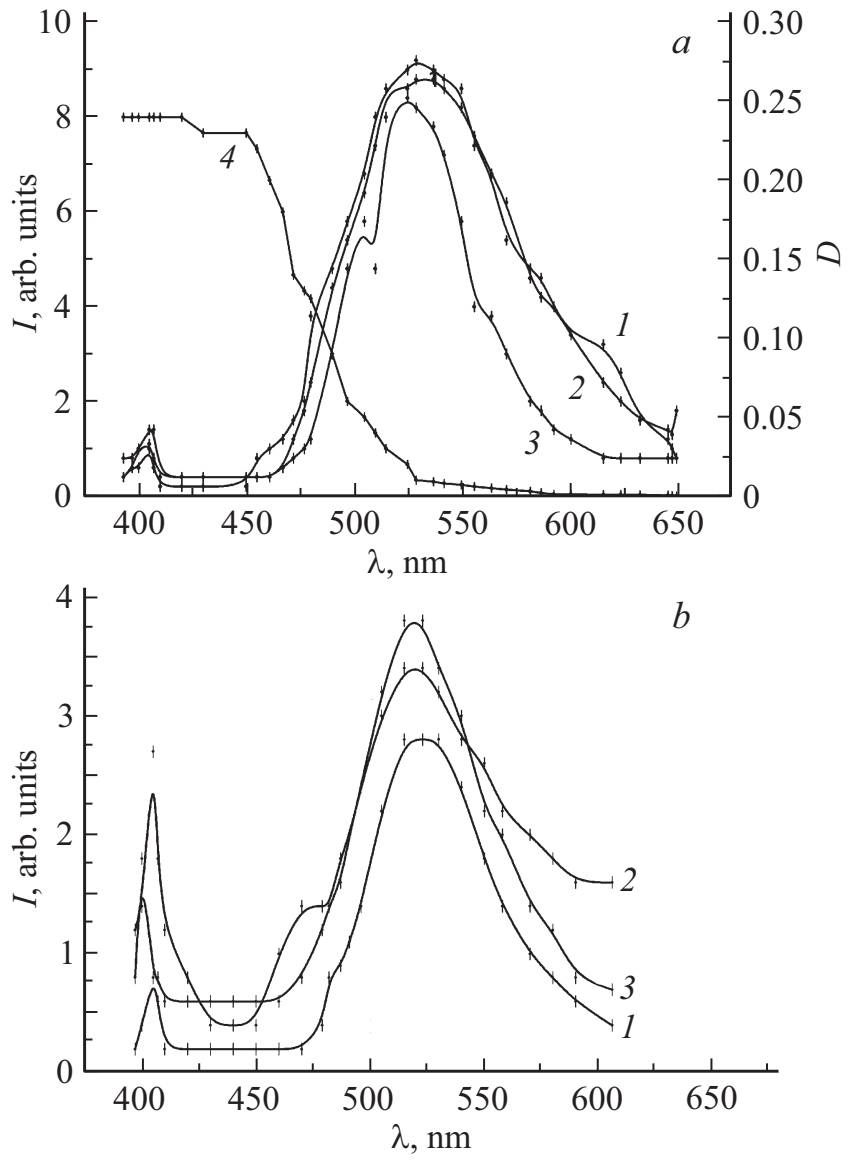

Рис. 3. Спектры интенсивности восстановленного поля объекта: композиция № 1 (1), композиция № 2 (2), эталонный образец № 3 (3); спектр поглощения композиции № 2 (4) в матрице Jel $(a)$ и в матрице PVP $(b)$.

люминесценции для всех образцов существенным образом зависит от типа матрицы. Интенсивность излучения в Jel приблизительно в 2 раза выше, чем в матрице PVP. Наблюдаемое тушение люминесценции в PVP матрице может быть связано с образованием комплекса с активной молекулой полимера [14].

На рис. 4 и 5 приведены измеренные поляризационные спектры восстановленного поля объекта для всех трех композиций в матрицах Jel $(a)$ и PVP $(b)$. На рис. 4 показано спектральное распределение коэффициента эллиптичности поляризации поля объекта (параметр $K_{e}$ ), на рис. 5 - спектральное распределение степени анизотропии люминесценции (параметр $r$ ).

Как видно из приведенных рисунков, у поляризационных спектров восстановленного поля объекта (для всех трех композиций регистрирующих сред различного химического строения) в обеих матрицах Jel и PVP имеются спектральные области, для которых значения коэффициента эллиптичности поляризации поля объекта $K_{e} \approx 1$, а значения $r \approx 0$. Это означает, что в спектральном диапазоне $\approx(420-460 \mathrm{~nm})$ состояние поляризации восстановленного поля объекта отличается 

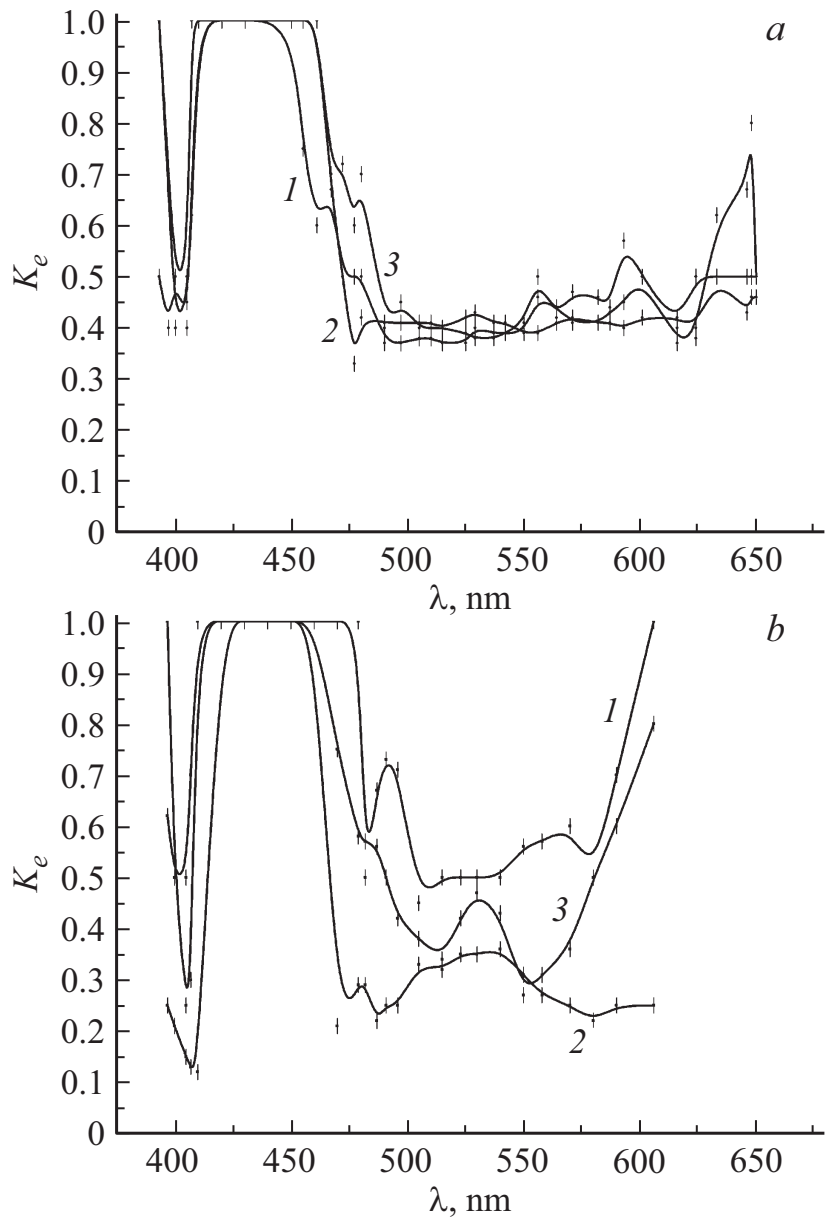

Рис. 4. Коэффициент эллиптичности поляризации (параметр $\left.K_{e}\right)$ восстановленного поля объекта: в матрице Jel $(a)$ и в матрице PVP $(b)$ : композиция № 1 (1), № 2 (2), эталонный образец № 3 (3).

от состояния поляризации линейно поляризованного регистрирующего лазерного излучения, и превращается в циркулярно поляризованное. В длинноволновом диапазоне $\approx 460-660 \mathrm{~nm}$, состояние поляризации восстановленного поля объекта - эллиптически поляризовано $\left(K_{e} \leq 1, r \geq 0\right)$.

Наблюдаемые особенности характера наведенной поляризованным светом анизотропии $\mathrm{PhL}$ (состояние поляризации восстановленного поля объекта) могут быть интерпретированы с помощью модели анизотропного осциллятора [20]. Согласно этой модели, изменение состояния поляризации анизотропных излучающих осцилляторов при фиксированной длине волны возбуждающего света может быть истолковано с точки зрения раздельных осцилляторов поглощения и излучения.

Из приведенных рисунков видно также, что матрица Jel в пределах погрешности эксперимента не влияет на значения степени анизотропии люминесценции и коэффициента эллиптичности поляризации поля объекта. В матрице PVP заметен существенный разброс значений этих параметров в зависимости от химического состава используемых композиций. Из теории известно, что степень анизотропии люминесценции уменьшается с увеличением симметрии молекул [21], поэтому по величине степени анизотропии можно судить о природе молекул красителя. Взаимное влияние донорных красителей Lucifer Yellow и Coumarin 466 с активной матрицей PVP (композиция № 2) может приводить к возникновению сложных комплексов [14], образуя более симметричную структуру, чем и вызвано уменьшение значений степени анизотропии люминесценции восстановленного поля объекта для данной композиции.

Опираясь на полученные результаты, показана возможность проведения записи и реконструкции, мультиплексных поляризационно-люминесцентных динамических голограмм на полученных регистрирующих материалах (композициях) почти во всей видимой спектральной области (414-700 nm).

Как указывалось выше, для поляризационного анализа пучка, соответствующего восстановленному мнимому изображению поля объекта, использовалась поляризационно-голографическая дифракционная решетка анизотропного профиля.
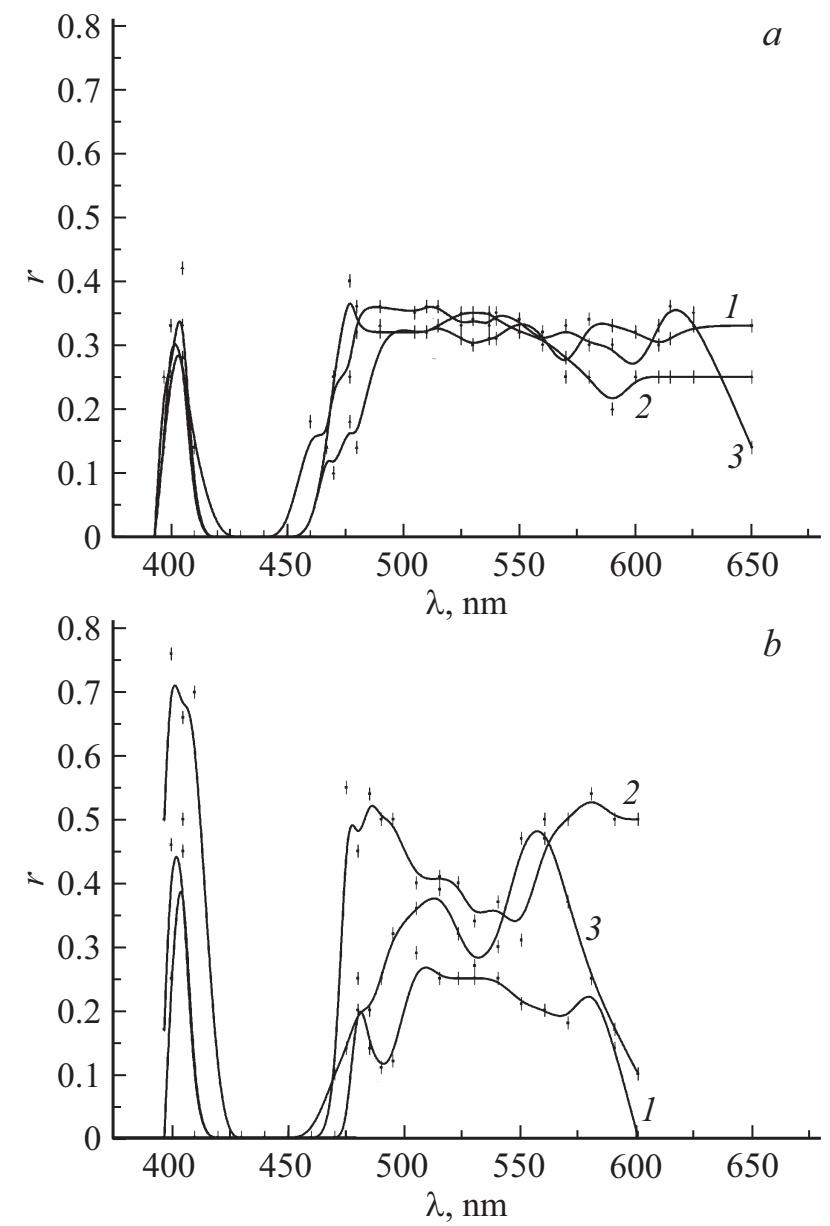

Рис. 5. Степень анизотропии люминесценции (параметр $r$ ) восстановленного поля объекта в матрице Jel $(a)$, в матрице PVP $(b)$ : композиция № 1 (1), композиция № 2 (2), эталонный образец № 3 (3). 


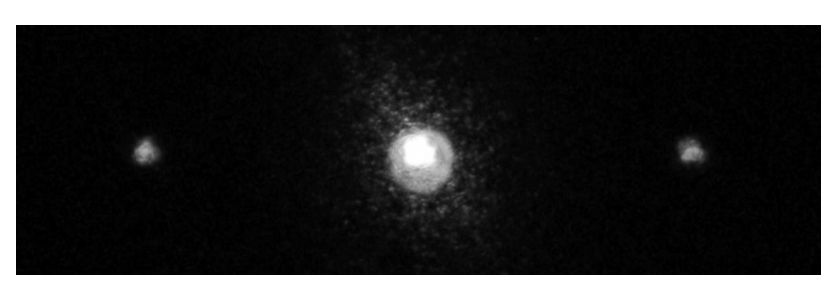

Рис. 6. Картина дифракции восстановленного изображения волнового поля объекта на решетке анизотропного профиля (длина волны эмиссии $\lambda=593 \mathrm{~nm} ; K_{e} \leq 1, r \geq 0$ ).

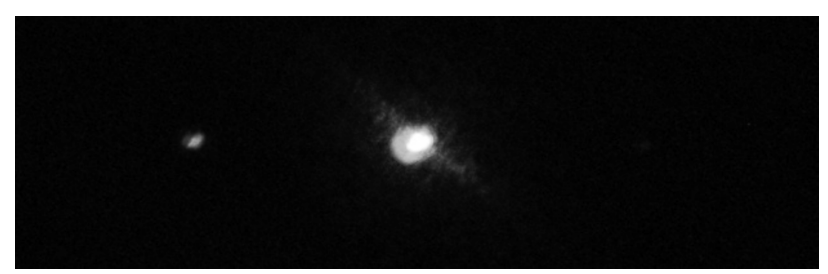

Рис. 7. Картина дифракции изображения восстановленного волнового поля объекта на решетке анизотропного профиля (длина волны эмиссии $\lambda=450 \mathrm{~nm} ; K_{e} \leq 1, r \geq 0$ ).

На рис. 6 приводится картина дифракции восстановленного изображения волнового поля объекта на длине волны эмиссии $\lambda=593 \mathrm{~nm}\left(K_{e} \leq 1, r \geq 0\right)$. В центре видно недифрагированное эллиптически поляризованное изображение восстановленного поля объекта (нулевой порядок дифракции). Слева и справа от него правои лево-циркулярно поляризованные пучки, дифрагированные соответственно в $+1-$ й и -1 -й порядки. Это показывает, что состояние поляризации восстановленного поля объекта на длине волны эмиссии $\lambda=593 \mathrm{~nm}$ $\left(K_{e} \leq 1, r \geq 0\right)$ эллиптически поляризовано. В качестве голограммной среды служили образцы композиции № 2 в матрице PVP, имеющие наибольшие значения абсолютных величин степени анизотропии фотолюминесценции в интервале длин волн 470-640 nm.

На рис. 7 приведена картина дифракции изображения восстановленного волнового поля объекта на длине волны эмиссии $\lambda=450 \mathrm{~nm}\left(K_{e} \leq 1, r \geq 0\right)$ на решетке анизотропного профиля. Как видно из приведенного рисунка, здесь полностью отсутствует след +1-го порядка дифракции и формируется только -1-й порядок дифракции. Это показывает, что состояние поляризации восстановленного поля объекта на длине волны эмиссии $\lambda=450 \mathrm{~nm}$ отличается от состояния поляризации линейно поляризованного регистрирующего лазерного излучения и имеет циркулярную поляризацию. В качестве голограммной среды служили образцы композиции № 2 в матрице PVP. Полученные результаты хорошо согласуются с экспериментальными результатами и с теорией.

\section{Заключение}

На основе матриц Jel и PVP получены люминесцентные поляризационно-чувствительные регистрирующие композиции, содержащие красители Lucifer Yellow и Coumarin 466, а также аминокислоту лизин, обладающих свойством поляризованной фотолюминесценции в широком спектральном диапазоне и выраженными эффектами векторных реакций.

Создан голографический спектрофлуориметр, дающий возможность записи и реконструкции мультиплексных динамических поляризационно-люминесцентных отражательных голограмм Денисюка, а также проведения количественных измерений поляризационно-люминесцентных параметров восстановленного поля объекта, зарегистрированного в полученных поляризационно-чувствительных люминесцирующих композициях.

Получены спектры поглощения и люминесценции для одной из композиций, показаны значительные величины стоксова сдвига.

Экспериментально показано, что при одинаковых условиях записи мультиплексных поляризационно-люминесцентных голограмм линейно поляризованным излучением лазера $(\lambda=405 \mathrm{~nm}, W=30 \mathrm{~mW})$ в регистрирующих композициях в зависимости от химического состава и матрицы Jel и PVP наблюдаются различия величин интенсивности поляризованной люминесценции (параметр I), степени анизотропии поляризации люминесценции (параметр $r$ ) и коэффициента эллиптичности (параметр $K_{e}$ ) поляризации восстановленного поля объекта. Это позволяет судить о природе различных ингредиентов, входящих в состав композиций, а также о фотоанизотропных свойствах сред в зависимости от активности матрицы.

На полученных регистрирующих материалах (композициях) экспериментально показана возможность мультиплексной записи и наблюдения за несколькими изображениями анизотропно-гиротропного объекта одновременно, если они закодированы разными частотами эмиссии и (или) состоянием поляризации.

Необходимо продолжить исследования по оптимизации созданных сред путем введения дополнительных допантов, изменения кислотно-щелочного баланса матрицы, технологических режимов, а также работать над созданием новых композиций для получения высокоэффективных сред для поляризационнолюминесцентных голограмм. Кроме того, на наш взгляд, комбинирование недеструктивного и безопасного для исследования различных биологических систем метода поляризационно-люминесцентной голографии с другими поляризационно-люминесцентными спектральными методами измерения резко повышает общую информативность исследования и значительно расширяет область применения данного метода. 


\section{Конфликт интересов}

Авторы заявляют, что у них нет конфликта интересов.

\section{Список литературы}

[1] Какичашвили Ш.Д. // Открытия, изобретения. 1979. № 38.

[2] Тарасашвили В.И., Пурцеладзе А.Л. // Опт. и спектр. 2007. T. 103. № 6. С. 1046.

[3] Желтов А.Я., Степанов Б.И., Шавердова В.Г. // ЖПС. 1990. T. 52. C. 280.

[4] Пуриеладзе А.Л., Тарасашвили В.И., Шавердова В.Г., Петрова С.С. // ЖПС. 2014. Т. 81. № 1. С. 65.

[5] Weigert F. // Verhandl. Deutschen Physik. Ges. 1919. Bd. 21. S. 479.

[6] Какичашвили Ш.Д., Шавердова В.Г. Фотоанизотропные и фотогиротропные явления в конденсированных средах и поляризационная голография. Тбилиси: Мецниереба, 1987. C. 48.

[7] Solano C., Lessard R.A. // Appl. Opt. 1985. V. 24. N 12. P. 1776. doi 10.1364/AO.24.001776

[8] Шавердова В.Г., Петрова С.С., Пуриеладзе А.Л., Тарасашвили В.И., Оболашвили Н.З. // Опт. и спектр. 2017. T. 123. № 3. C. 458. doi 10.7868/S0030403417090288

[9] Бекбергенов Б.М., Житников В.Г. // Антибиотики и химиотер. 1988. Т. 33. № 1. С. 72.

[10] Tarasashvili M.V., Alexidze N.G. // Bioastronomy 2007: Molecules, Microbes and Extraterrestrial Life, Puerto Rico, ASP Conference Series. 2009. V. 420. P. 243. http://articles.adsabs.harvard.edu/full/2009ASPC..420..243T

[11] Тарасашвили В.И., Петрова С.С., Пуриеладзе А.Л., Шавердова В.Г., Оболашвили Н.З. // Опт. и спектр. 2018. T. 125. № 4. C. 535. doi 10.21883/OS.2018.10.46707.18

[12] Smith D.S., Eremin S.A. // Analytical and Bioanalytical Chem. 2008. V. 391. N 5. P. 1499. doi 10.1007/s00216-008-1897-z

[13] Еремин С.А. // Биохимические методы анализа / Под ред. Дзантиева Б.Б.; М.: Наука, 2010. С. 368.

[14] Петрова С.С., Чичинадзе Н.М., Шавердова В.Г. // ЖТФ. 2005. T. 75. № 2. C. 89.

[15] Денисюк Ю.Н. // Опт. и спектр. 1963. Т. 15. № 4. С. 522.

[16] Пуриеладзе А.Л., Тарасашвили В.И., Шавердова В.Г., Петрова С.С. // ЖПС. 2014. Т. 81. № 1. С. 65.

[17] Танин Л.В., Танин В.А. // Мир голографии. 2017. Т. 3. № 1. C. 4.

[18] Толстик А.Л. // Мир голографии. 2017. Т. 3. № 1. С. 24.

[19] Какичашвили Ш.Д., Шаталин И.Д. // Фотоанизотропные и фотогиротропные явления в конденсированных средах и поляризационная голография. Тбилиси: Мецниереба, 1987. C. 72

[20] Вавилов С.И. Собр. соч. М., 1952. 129 с.

[21] Бабушкин A.A. и др. Методы спектрального анализа. М.: МГУ, 1962. $509 \mathrm{c}$. 